\title{
A Critical Study on Translation of the Analects:
} An Ideological Perspective

Fan Min, Shanghai Lixin University of Accounting and Finance, Shanghai, China

\begin{abstract}
"Ideology" shapes our discourse practices and is closely related to the translation activities. This paper attempts to explore how ideological factors influence the cultural transmission of Confucianism through a comparative analysis of the three versions of the great Chinese classical works the Analects that are translated by Raymond Dawson, Ames and Rosemont, and Edward Slingerland. In this comparative study, the paper focuses on the important role of the ideology in the process of translating the Analects through a discussion of the possible reasons behind the translation strategies. The paper concludes with a consideration of how ideology imposes on translation for cultural communication, negotiation, and transformation. It is hoped to demonstrate the ideological influences on the translated works, provide useful suggestions for the translation of Chinese classical works, and promote the international dialogue between China and the Western world.
\end{abstract}

\section{KEYWORDS}

The Analects, Confucian Terms, Ideology, Stylistic Features, Translation Strategies

\section{INTRODUCTION}

As is well known, few works have shaped their country's civilization more profoundly than the Analects, which lays the solid foundation for the social, ethical and intellectual system of China. With the rise of China as a major force in the world's economic and political order, as a soft power, the Chinese traditional culture embodied in the Analects has aroused much more interests in both China and foreign countries. However, due to the vast cultural differences between China and West, there is a profound cognitive asymmetry in the transmission of the Analects in the world.

This cultural phenomenon is faced with great challenges for translators: how to effectively convey the traditional Chinese culture such as Ren(benevolence), $Y i$ (loyalty), Li(ceremony), Zhi(wisdom), $X i n$ (honesty) to the Western world. The word "Effectively" is used to refer to the fact that the translated version should be accurate and faithful in both content and style, and the versions should be idiomatic and easy to understand. In this sense, a comparative study of the translation of the Analects from an ideological perspective is significant as it can demonstrate the reasons and strategies that lie behind the translation decisions.

According to Maria Calzada- Perez, culture is commonly taken to be an integrated system of learned behavior patterns that are characteristic of the members of any given society, whereas ideology as a sub-set of culture consists of the set of ideas, values and beliefs that govern a community by virtue of being regarded as the norm (Calzada-Perez, 2003, pp.5-6). That is to say, everyday "culture" is

This article, published as an Open Access article on February $1^{\text {st }}$, 2021, in the gold Open Access journal, International Journal of Translation, Interpretation, and Applied Linguistics (IJTIAL) (converted to gold Open Access January 1st 2021), is distributed under the terms of the Creative Commons Attribution License (http://creativecommons.org/licenses/by/4.0/) which permits unrestricted use, distribution, and production in any medium, provided the author of the original work and original publication source are properly credited. 
normally related to what is conventionally known as "society", in its ethnic sense of "the community of people living in a particular country or region and having shared customs, laws and organizations" (ibid). Our definition of ideology aims at enlarging this ethnic Ideology: it not only affects "societies", but also permeates groups of the most varied nature.

In this paper, the descriptive and critical study of the ideology and its influences on the translation of the Analects will be discussed. In the process of discussion, the following aspects are covered: understanding of ideology and its interrelations with translation, stylistic features of the Analects and its three versions, and ideological investigation into the translation process of the Analects.

\section{UNDERSTANDING OF IDEOLOGY AND ITS INTERRELATIONS WITH TRANSLATION}

Ideology is a complex and controversial concept. It can be understood in many ways according to the specific context, which can reflect diverse epochs and different lines of thought.

The philosophical term "ideology" was coined by the French rationalist philosopher Destutt De Tracy, who intended to mean the systematic study of knowledge, beliefs, and ideas (Williams, 1976, p.126). According to Van Dijk, the nature of ideology is "a specific type of basic mental representations shared by the members of groups, and hence firmly located in the minds of people" (Van Dijk, 1998, p.48). It is therefore supposed that these group members belong to a given society, and these ideologies are (re)produced through discourse. The discourse dimension of ideologies explains how ideologies influence our daily texts, and how discourse is involved in the understanding and (re)production of ideology in society. Thompson defines the concept of "ideology" as follows: (1) descriptive views of ideology: positions, attitudes, beliefs, perspectives, etc. of social groups with reference to relations of power and domination between such groups; (2) the critical view of ideology: representations of aspects of the world which can be shown to contribute to establishing, maintaining and changing social relations of power, domination and exploration; (3) ideological representations can be identified in texts. They probably have a schematic structure that represents the self-image of each group, featuring membership devices, aims, activities, norms and resources of each group. Ideologies feature the basic principles that organize the attitudes shared by the members of a group(Calzada-Perez, 2003, p.5). According to Verschueren, "Ideology is related to ideas, beliefs, and opinions, as such, do not make ideology. Simplifying a bit, they are merely 'contents of thinking', whereas ideology is associated with underlying patterns of meaning, frames of interpretation, world views, or forms of everyday thinking and explanation" (Verschueren,2012, p.7).

In this way, the selective representations of expressions and rhetorical devices lead us to the view that it is through discourse and other semiotic practices that ideologies are formulated, reproduced and reinforced. Ideology is thus understood as the social representations shared by members of a group and used by them to accomplish everyday social practices and activities. These representations are organized into systems which are deployed by social groups in order to understand, figure out and render intelligibly the way society works in terms of power or knowledge. As such, ideology is formed by discourses that have specific consequences for relations of power at various levels of social groups. Meanwhile, ideology means reproduction and maintenance of power relations through the manipulation of meaning in order to hide these relations. Just like what Barker and Galasinski has said, "ideologies are structures of signification which constitute social relations in and through power. If meaning is fluid-a question of difference and deferral-then ideology can be understood as the attempt to fix meaning for specific purposes" (Barker \& Galasinski, 2001, p.66).

Regarding the interrelations between ideology and translation, Fawcett states that the issue of ideology in translation is very difficult to study because people tend to consider all human activities as ideologically motivated (Fawcett,1998, p.106). Venuti believes that "any language use is a site for power relations" (Venuti,1998,p.9), and claims that weak cultures are dominated by strong cultures. According to Hatim and Mason, "behind the systematic linguistic choices we make, there is inevitably 
a prior classification of reality in ideological terms" (Hatim \& Mason, 1990, p.161). Bassnett and Lefevere further point out that ideology is associated with "the society in which the translator lived, i.e. the conceptual grid that consists of opinions and attitudes deemed acceptable in a certain society at a certain time, and through which readers and translators approach texts" (Bassnett \& Lefevere, 2001, p.48).

The insights provided by these ideological studies advance our comprehension of the way ideology shapes texts and the way textual practices help to maintain, reinforce or challenge ideologies. In addition, the above understanding of ideology and translation help us reinforce the understanding towards social factors, power relations, textual structures, and the rhetorical purposes of discourse practices and textual interactions.

Based on the above-mentioned considerations, the following points could be emphasized in the discussion of the translation of the Analects: the critical view of the stylistic representations in the Analects and its different versions, and the manipulation of power in different translation strategies. In doing so, we hope to provide evidence of the ideological consequences of translators' choices and to show the reasons behind the translation strategy.

\section{STYLISTIC FEATURES OF THE ANALECTS}

The Analects, or Lunyu (lit. "ordered sayings"), "purports to be a record of the teachings of Kongzi and his disciples." (Slingerland, 2003, p. xiii). In other words, the Analects "is not a 'book' in the sense that most modern Westerners usually understand a book - that is, a coherent argument or story presented by a single author, to be digested alone in the quiet of one's study. It is instead a recordsomewhat haphazardly collected and edited together at an unknown point in history" (Slingerland, 2003, p. Vii).

The chapter arrangement in the Analects is not necessarily reasonable; even between the two chapters, there is not necessarily any correlation. And these chapters are by no means written by one person. However, the overall structure design of the chapters of the Analects seems to have been carefully arranged. Specifically speaking, the Analects starts from the conscious learning to the ability to acquire knowledge of life and etiquette, and in the last chapter Confucius put forward that people should "know three things", namely "knowing fate", "knowing rites" and "knowing words". For example, Confucius said, "If you don't know fate, you can't be a gentleman; if you don't know etiquette, you can't exist in the society; if you don't know what people say, you can't understand others"(Yang, 2017, p.238). Confucius believes that fate is objective and unpredictable. A gentleman needs to learn how to settle down, how to behave well, and how to be familiar with human nature. Only in this way can he truly stand in society. The Analects concludes with this chapter, which corresponds to the first chapter. Thus, the structure and content of the book are integrated.

The style of the Analects inherits the discourse construction model of "small words with significant meanings" in the Spring and Autumn Period. Taking the verbal dao 道as the example, according to Ames and Rosemont, "for Confucius, dao is primarily rendao 人道, that is, 'a way of becoming consummately and authoritatively human.' As 15.29 tells us: 'It is the person who is able to broaden the way, not the way that broadens the person'"(Ames \& Rosemont, 1998, p.45). In such a way, the Analects puts facts into various practical relations through indicative statements, and indicates the attitudes towards facts. In addition, the Analects also intends to narrow the boundary between oneself and the sacred text by rhetoric expressions so as to make the meaning self-evident. The Analects always encourages the disciples of Confucius to approach the truth and indicates the way, but never expresses the ultimate truth directly. Slingerland indicates that "As we see throughout the text, Confucius' comments are often intended to elicit responses from his disciples, which are then corrected or commented upon by the Master. Therefore, these "ordered sayings" of Confucius were originally embedded in a conversational context within which their meaning could be gradually 
extracted" (Slingerland, 2003, p. Vii). As the Analects is so concise, cryptic and hard to understand, it is necessary for translators to add the context in target versions so as to make the text easy to read.

\section{STYLISTIC FEATURES OF THE THREE VERSIONS}

The selected three versions are translated by Raymond Dawson, Roger T. Ames \& Henry Rosemont, and Edward Slingerland respectively. The reasons why the three versions are selected lie in that the three versions are successful and evident in terms of stylistic features . In addition, as ideologies find their clearest expressions in their choices of language, thus, from the analysis of the three versions, we can find the significant ideological influences that underlie the translation process.

These three translators work in different cultural environments. Dawson is a professor in Oxford, UK. His research interests mainly include history, philosophy and literature. Dawson published many works related with Chinese language and culture, and tried to eliminate the misunderstandings of Western readers towards China. Ames is a Professor of Chinese philosophy at the University of Hawaii, Director of its Center for Chinese Studies, and also a Humanities Chair in Peking University. His works are always recognized as the landmarks of contemporary Chinese military and philosophical studies. Slingerland, professor of Asian Studies at the University of British Columbia, Canada, has made great achievements in comparative religion, cognitive science, cognitive linguistics, classical Chinese language and culture, the relationship between the humanities and the natural sciences.

As mentioned above, the Analects is characterized by "careful arrangement", "small words with significant meanings", "rhetoric devices", and "cryptic meanings". In addition, there exist vast differences between Chinese culture and Western culture. Chinese culture is characterized by innumerable correlative and indivisible things/events, making a whole in terms of correlations, societal harmony, indivisibility and continuity. Western culture is characterized by individuality, conflict, dualism and transcendentalism. Regarding the massive understanding of the differences on superficial cultural issues, we should apply the above two interpretive modalities in contrasting the structural differences of the Chinese and Western intellectual and cultural tradition in order to develop plausible explanations. The understanding of different cultures and the comparative hermeneutics based upon the two modalities will necessarily lead to a better understanding of the world on the part of China. Therefore, the translation of the Analects from Chinese to English will be adjusted according to target cultural norms.

Table 1 shows a comparative analysis of stylistic features of three versions in terms of discourse construction and rhetorical features:

This stylistic features of the three versions have important practical guiding significance in promoting the acceptability of Chinese classics in the foreign countries. Dawson, Ames and Slingerland all use the compensation strategies in their versions. For example, they offer the explanations in an introduction or in a preface, notes or appendixes, etc., which help English readers further understand the Analects and its traditional Chinese cultural thoughts. Yet, they adopted different explanatory approaches, for example, Dawson used endnotes to explain Confucian terms and give a very brief introduction to the historical background for those readers who are totally unfamiliar with ancient Chinese history. Ames and Rosemont used the philosophical interpretation in their versions. Slingerland adopted a theme explanation at the beginning of each chapter, which played an important role in outlining and highlighting the contents of the whole chapter for readers. In addition, Slingerland adopted the "thick translation" approach to achieve the full original meaning by adding annotations and accompanying comments, thus enabling the text to survive in a rich linguistic and cultural context. 
Table 1. Stylistic features of the three versions

\begin{tabular}{|c|c|c|c|}
\hline $\begin{array}{l}\text { Translators } \\
\text { Parameters }\end{array}$ & $\begin{array}{c}\text { Dawson's Version } \\
\text { (1993) }\end{array}$ & $\begin{array}{c}\text { Ames\& Rosemont's } \\
\text { Version (1998) }\end{array}$ & $\begin{array}{c}\text { Slingerland's Version } \\
\text { (2003) }\end{array}$ \\
\hline $\begin{array}{l}\text { Discourse } \\
\text { Construction }\end{array}$ & $\begin{array}{l}\text { Introduction; } \\
\text { Note on the text; } \\
\text { Note on the Translation of } \\
\text { Key Terms; } \\
\text { Note on Romanization; } \\
\text { Select Bibliography; } \\
\text { Chronological Survey; } \\
\text { The Analects; } \\
\text { Explanatory Notes; } \\
\text { Index }\end{array}$ & $\begin{array}{l}\text { Translators' preface; } \\
\text { Acknowledgements; } \\
\text { Introduction; } \\
\text { The Analects of Confucius: } \\
\text { A Philosophical Translation; } \\
\text { Appendix (I, II) } \\
\text { Bibliography of Works } \\
\text { Cited }\end{array}$ & $\begin{array}{l}\text { Preface; } \\
\text { Acknowledgments; } \\
\text { Conventions; } \\
\text { Introduction; } \\
\text { Traditional Chronology; } \\
\text { Analects; } \\
\text { Romanization; } \\
\text { Appendix (1.2.3.4.5); } \\
\text { Bibliography. }\end{array}$ \\
\hline $\begin{array}{l}\text { Rhetorical } \\
\text { Features }\end{array}$ & $\begin{array}{l}\text { Plain; } \\
\text { easy to understand }\end{array}$ & Philosophical insights & $\begin{array}{l}\text { Cognitive } \\
\text { commentaries }\end{array}$ \\
\hline
\end{tabular}

\section{IDEOLOGICAL INVESTIGATION INTO THE TRANSLATION PROCESS OF THE ANALECTS}

By focusing on ideological influence and by contrasting the language structures and cultural differences that exist in both English and Chinese cultural tradition through comparative hermeneutics, we may be able to penetrate and discuss the reasons that lie behind the translation strategies.

\section{E.g.1 哀公问社于宰我。宰我对曰:“夏后氏以松,殷人以柏,周人以栗,曰,使民战栗。”子闻之， 曰:“成事不说,遂事不谏,既往不各。(《论语·八佾》)}

\section{Dawson}

Duke Ai asked about the altar to the earth god. Zai Wo replied saying: 'The Xia used the pine, the men of yin used the cypress, and the men of Zhou used the chestnut, saying that it would make the people tremble.' When the Master heard this, he said: "What is over and done with one does not discuss, what has taken its course one does not complain about, and what is already past one does not criticize."

\section{Ames \& Rosemon}

Duke Ai asked Zaiwo about the altar pole to the god of the soil. Zaiwo replied: "The Xia clans used wood of the pine (song 松), the Yin peoples used the cypress (bai 柏), and the Zhou peoples used the chestnut (li 栗). It is said that they wanted to make the people fearful (zhanli 战栗).” When the Master heard of this, he said: "You don't discuss what is finished and done with; you don't remonstrate over what happens as a matter of course; you don't level blame against what is long gone."

\section{Slingerland}

Duke Ai asked Zai Wo about the altar to the soil. Zai Wo replied, "The clans of the Xia sovereigns used the pine tree, the Shang people used the 
cypress tree, and the Zhou people used the chestnut tree (li). It is said that they wanted to instill fear ( $l i$ 栗) in the people."

Having been informed of this, the Master remarked, "One does not try to explain what is over and done with, one does not try to criticize what is already gone, and one does not try to censure that which is already past."

From the comparison of the three versions, we find that these three versions all convey the original text under the interpretative context, which can give the English-language reader a hint of the richness of the context. Specifically speaking, Dawson explained the Confucian term in the endnote; Ames and Rosemont translated with the Chinese characters and Pinyin form; Slingerland added the historical background and gave the explanation upon the use of puns, such as the humorous use of the trees “松,柏,栗”.

Dawson explained “栗” in the endnote as follows, “tremble: written with the same character as the word for 'chestnut'. The passage refers to the planting of trees round the altar. It appears that Master Kong did not like Zai Wo's interpretation of the use of chestnuts, presumably because it implied that the revered Zhou had employed terrorism" (Dawson,1993, p.88). Dawson translated the version so as to make the non-specialist readers understand the original text quite easily. "I do feel that one should get as close to the original as possible, even if the result is sometimes a little outlandish. I do not think that it is entirely virtuous to produce a version which reads as if it were written at the end of the twentieth century...but I think it is better to use everyday English words accompanied by caveats about their meaning" (Dawson 1993, p. xvi). According to Dawson, "many of the brief utterances found in the Analects may be seen as seminal expressions of some of the typical ideas of Chinese civilization. This is the main importance of the work, as I have tried to show in some of my explanatory notes" (Dawson, 1993, p. xiii).

Ames and Rosemont translated 栗into “chestnut (li 栗)” instead of “chestnut”. They translated the original text with the belief that "the Confucian way is a path through a world that differs significantly from ours in important respects" (Ames \& Rosemont, 1998,p.X). They pointed out that "translation and interpretation are inextricably linked. No words, or strings thereof, carry with them any precise cognates in another language, and dictionaries, etymological or otherwise, can seldom function as the final arbiters" (Ames \& Rosemont, 1998, p.282). There is "no real alternative but to cultivate a nuanced familiarity with the key Chinese vocabulary itself" (Ames, 2017, p.8). In addition, "the character of Chinese Confucianism being what it is, many of the terms and concepts crucial to this tradition accrued decidedly different connotations from their original meanings with the passage of centuries" (Hall \&Ames, 1987,p.xiii). In this sense, Ames and Rosemont reconstructed the philosophical lexicon associated with the Chinese language and culture. There is a trend in comparative studies to approach Chinese thought from a Western philosophical perspective, by reference to frameworks, concepts, or issues found in Western philosophical discussions. Conversely, in the contemporary literature, we rarely find attempts to approach Western philosophical thought by reference to frameworks, concepts, or issues found in Chinese philosophical discussions. Therefore, "the cumulative result of their reconstruction of the Confucian world is a set of new readings for what have become technical terms in Confucian scholarship" (Hall \&Ames, 1987, p. XIV).

Slingerland translated 栗into “chestnut tree (li)", and in his endnotes further gave an explanation of the meanings of the three puns. "It is possible that the other tree names had similar double meanings as the result of puns: “pine" (song 松 being graphically similar to rong容 (“accommodating”) and having the phonetic gong公 (“just, public"; “lord”) and “cypress” (bo柏) being similar to po 迫 (“to press”) or pa 怕(“quiet, still”; “to fear”) ; Zai Wo is playing upon a graphic pun between li 栗

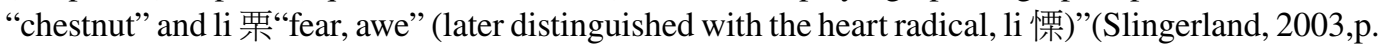
26), etc. These discourse practices and textual interactions reflect the intentions of the translator. Slingerland's translation was designed primarily for non-specialists and is based on "Cheng Shude, one of the most important of 20th-century Chinese students of the text"(Slingerland, 2003, p. ix). 
He explained that "by providing alternative interpretations of individual passages and identifying where various understandings are coming from, as well as by pointing the reader in the direction of works that contain more detailed discussions of the issues at hand, I am trying to give back at least a measure of this power to the English-language reader. Not too much, of course, because a certain measure of control has to be exerted to avoid producing utter nonsense, but something approaching the maximum amount of power someone cut off from the text in its original language can reasonably hope" (Slingerland, 2003, p. ix). He further explained that, "Hopefully the background information provided above and the commentary provided in the translation that follows will give the reader some sense of why the Analects has been so influential, and allow her to see the text as more than merely a historical curiosity or collection of quaint homilies, but as an expression of a powerful religious and moral vision—one still capable of both speaking to and instructing us today" (Slingerland, 2003, p. $\mathrm{xxv}$ ).

From the above analysis, we can find that the ways in which the beliefs, ideas, and opinions of the three translators are discursively used. Their contents of thinking, different forms of expression and rhetorical purposes in their versions are important labels for ideologies.

\section{E.g.2 子曰:“吾十有五而志于学,三十而立,四十而不惑,五十而知天命, 六十而耳顺, 七十而从心 所欲, 不逾矩。” (《论语·为政》)}

\section{Dawson}

The Master said: "At fifteen I set my heart on learning, at thirty I was established, at forty I had no perplexities, at fifty I understood the decrees of Heaven, at sixty my ear was in accord, and at seventy I followed what my heart desired but did not transgress what was right."

Ames \& Rosemont: The Master said: "From fifteen, my heart-and-mind was set upon learning; from thirty I took my stance; from forty I was no longer doubtful; from fifty I realized the propensities of tian (tianming天命); from sixty my ear was attuned; from seventy I could give my heart-and-mind free rein without overstepping the boundaries."

Slingerland: The Master said, "At fifteen, I set my mind upon learning; at thirty, I took my place in society; at forty, I became free of doubts; at fifty, I understood Heaven's Mandate; at sixty, my ear was attuned; and at seventy, I could follow my heart's desires without overstepping the bounds of propriety."

From the comparative study of the three versions, we find the sentence structure, content and some key words are translated differently by the three translators. Ames and Rosemont used a "from" structure, while Dawson and Slingerland used an "at" structure. These differences in sentence structure are related with the translators' different intentions and ideologies. Ames and Rosemont's version indicates a relationally-constituted notion of persons. Their version reflects Chinese philosophical orientations, which demonstrate "what" makes the human experience meaningful and functional. The important philosophical concern here "is that the classical Confucian sense of order is processional and hence provisional.... ritually constituted community requires that the values of the tradition be internalized and personalized" (Ames \& Rosemont, 1998, p.281). In the minds of Chinese people, the cosmos has always been nothing more than a continuous stream, a kind of flow, all of the things and events of the cosmos are just a continuing process. Chinese people focus on human becomings, reflexivity, collaboration, multilateralism in relations, a processual and emergent cosmic order, the inseparability of one and many, and the phenomena of achieving personal identity through "enrolling and embodying". Ames pointed out that "natural languages and their structures tend to reveal the default worldview and distilled common senses of the cultures they speak. Said another way, our languages 'speak' us as much as we speak our languages" (Ames, 2017, p. 7). In this sense, the 
preposition "from" instead of "at" is used, as the English word "from" indicates a process rather than a point.

Dawson stated that this saying reflected that Confucius eventually attains unthinking adoption of moral standards as a result of the process of self-cultivation and the internalization of moral values (Dawson,1993, p.85). Dawson pointed out that "Master Kong is not depicted in as striving to analyze ethical terms in the manner of much western moral philosophy. Instead his primary purpose is to assist the individual in the essential process of self-cultivation, so making him fit to take part in government" (Dawson,1993, p. xiii). Dawson emphasized the importance of context, and tried to make his version as intelligible as possible to people of Western culture so as to achieve inter-cultural communication. Dawson pointed out that "the basic problem is that Classical Chinese is heavily dependent on context since there is no built-in indication of whether a word is functioning as a noun, verb, or any other part of speech. If it is functioning as a verb, there is no indication of tense or of whether it is being used in the first, second, or third person or indeed, except in the negative, whether it is in the indicative or the imperative mood" (Dawson,1993, pp. xvi-xvii).

Slingerland pointed out that this saying emphasized the transformative effect of the environment upon one's character. He explained that "we can see his evolution as encompassing three pairs of stages. In the first pair (stages one and two), the aspiring gentleman commits himself to the Confucian Way, submitting to the rigors of study and ritual practice until these traditional forms have been internalized to the point that he is able to 'take his place' among others. In the second pair, the practitioner begins to feel truly at ease with this new manner of being, and is able to understand how the Confucian Way fits into the order of things and complies with the will of Heaven. The clarity and sense of ease this brings with it leads to the final two stages, where one's dispositions have been so thoroughly harmonized with the dictates of normative culture that one accords with them spontaneously-that is, the state of wu-wei" (Slingerland, 2003, p. 9).

Regarding the translation of some key Confucian terms, from the comparative study of different versions, we find that Ames and Rosemont's version has many neologisms, for example, the Chinese Confucian term 天 into "tian (天)" is used instead of "God". Ames and Rosemont pointed out his reason to translate in such a way: "Indeed, word-for-word translation can in the long run the counterproductive to the extent that it encourages students to inadvertently rely upon the useful implications of the translated term (i.e. 'Heaven') rather than on the range of meaning implicit in the complex and organically related Chinese terms themselves (i.e. tian天). When one reads tian 天 as 'Heaven' rather than as tian 天, one reads the text very differently" (Ames, 2017,p.8). By way of analogy, Ames and Rosemont translated the other Confucian terms in a similar way, such as the translation of 天命 as "propensities of tian (tianming天命)" . "It is in this effort to take Chinese philosophy on its own terms, then, that we must begin from the interpretative context by taking into account the tradition's own indigenous presuppositions and its own evolving self-understanding. We must be aware of the ambient, persistent, assumptions that have given the Chinese philosophical narrative its unique identity over time. It is these presuppositions that inform the philosophical vocabulary and set parameters on their meanings"(Ames, 2017, p.9).

Dawson translated 天命 into the "decrees of Heaven". Dawson pointed out that "Master Kong is depicted as displaying an agnostic attitude towards ghosts and spirits, although they are seen as part of the general experience of life. On the other hand, he is very conscious of the role of Heaven who 'created the virtue' in him, and upon whom all riches and honours depend, while others are described in the Analects as believing that Heaven is using the Master and will grant that he becomes a sage. A more impersonal 'fate' or 'destiny(ming)', a word which is also used in its more literal sense of 'decree' or 'command', also occurs commonly. It reflects the feeling which must be common to all cultures that, despite all our efforts, what happens is really out of our hands, although commands and decrees can of course be disobeyed and one can, for example, lay down one's life and so not accept one's predestined span" (Dawson,1993, p. xxvi). Regarding the choice of the appropriate version, Rawson explained that, "All writers of English carry around a heavy baggage of preconceptions which 
derive ultimately from Western philosophical and religious beliefs. In translating from a cultural sphere which does not share these prejudices and from a language whose very nature may to some extent impose its own world-view we are, however, bound to use terms which depend heavily upon Western traditions" (Rawson, 1993, p. xxvii).

Slingerland translated “天” as the "Heaven's Mandate" and pointed out its following underlined meaning in his translated work: understanding the Mandate of Heaven is a prerequisite for delving into the Changes and Transformations. Preserving one's heart-mind and nourishing one's nature are the way by which to serve Heaven. Understood this way, "human nature" and the "Way of Heaven" collectively refer to the range of things that are beyond human control, and what the Master focused on was within human control, i.e. commitment to learning and the Confucian Way. Slingerland emphasized that the importance of adding notes is to make the dense and abstruse original text clear and comprehensible in the target version. Slingerland even cited Alice Cheang's comments and pointed out "what has been added is necessary in order to render the words of Confucius intelligible in another language, but the result is a text in which the balance of power is shifted towards the author (in this case the translator) and away from the reader" (Slingerland, 2003, p. viii).

From the above analysis, we find that the different choices of words and rhetorical devices of the three translators reflect their ideologies at different levels: at the lexical-semantic level, and at the grammatical-syntactic level. To be meaningful, "text features must be viewed within the necessary social embedding of all texts, since items considered in isolation will inevitably lack a significant ideological import. Whatever is said about the degree of freedom the translator has, the fact remains that reflecting the ideological force of the words is an inescapable duty" (Hatim \& Mason,1990, p.161).

\section{CONCLUSION}

Ideologies can be understood as the discourses which give meaning to social practices in the given society. Meanwhile, discourse can be understood as a site of power struggle in which the ideologies implicated by discursive choices are the subject of struggles for dominance. Through the comparative study of three versions of the Analects, this paper gives a descriptive and critical analysis of the influence of ideologies on the translation process of the Analects in various aspects. Due to different historical backgrounds, translation motivations, and translation strategies, the translators usually produce their own acceptable and intelligible way of understanding the world through the conscious or un-conscious manipulation of meaning in the target versions. Meanwhile, the ideologies can find the rhetorical label expressions in terms of reflection of textual style, conveyance of cultural content, consideration of reader's acceptance, and selection of translation strategies so as to realize the intercultural communication.

\section{FUNDING AGENCY}

Open Access Funding Provided by Shandong University (Weihai), China

\section{ACKNOWLEDGMENT}

This paper is funded by National Social Science Foundation Program: An Innovative Study on the International Communication Mechanism of the Chinese Classics based on the English Translation of the Analects (No. 17BYY063). 


\section{REFERENCES}

Ames, R. T. (2015). The Great Commentary (Dazhuan 大傳) and Chinese natural cosmology. International Communication of Chinese Culture, 2(1), 1-18. doi:10.1007/s40636-015-0013-2

Ames, R. T. (2017). Better late than Never: Understanding Chinese Philosophy and 'Translating It' into the Western Academy. Ethics and Education, 12(1), 6-17. doi:10.1080/17449642.2016.1270509

Ames, R. T., \& Rosemont, H. (Trans.). (1998).The Analects of Confucius: A Philosophical Translation. Ballantine.

Barker, C., \& Galasinski, D. (2001). Cultural Studies and Discourse Analysis. Sage Publications Ltd.

Bassnett, S., \& Lefevere, A. (2001). Constructing Cultures: Essays on Literary Translation. Shanghai Foreign Language Education Press.

Calzada-Perez, M. (2003). Apropos of Ideology. St. Jerome Publishing.

Dawson, R. (1993). Tran. Confucius: the Analects. Oxford University Press.

Fawcett, P. (1998). Ideology and Translation. In M. Baker (Ed.), Routledge Encyclopedia of Translation Studies (pp. 106-111). Routledge.

Hall, D. L., \& Ames, R. T. (1987). Thinking Through Confucius. State University of New York Press.

Hatim, B., \& Mason, I. (1990). Discourse and the Translator. Longman.

Van Dijk, T. A. (1998). Discourse as Social Interaction. Sage Publications Ltd.

Venuti, L. (1998). The Scandals of Translation: Towards an Ethics of Difference. Routledge. doi: $10.4324 / 9780203269701$

Verschueren, J. (2012). Ideology in Language Use. Cambridge University Press.

Williams, R. (1976). Keywords: A Vocabulary of Culture and Society. Fontana/Croom Helm.

Yang, B. J. (2017). (Trans.) The Analects of Confucius. China Publishing House. 